\title{
Systematic analysis of the ability of Nitric Oxide donors to dislodge biofilms formed by Salmonella enterica and Escherichia coli 0157:H7
}

\author{
Massimiliano Marvasi ${ }^{1}$, Charles Chen ${ }^{2}$, Manuel Carrazana ${ }^{2}$, lan A Durie ${ }^{1}$ and Max Teplitski ${ }^{1,3^{*}}$
}

\begin{abstract}
Biofilms in the industrial environment could be problematic. Encased in extracellular polymeric substances, pathogens within biofilms are significantly more resistant to chlorine and other disinfectants. Recent studies suggest that compounds capable of manipulating nitric oxide-mediated signaling in bacteria could induce dispersal of sessile bacteria and provide a foundation for novel approaches to controlling biofilms formed by some microorganisms. In this work, we compared the ability of five nitric oxide donors (molsidomine, MAHMA NONOate, diethylamine NONOate, diethylamine NONOate diethylammonium salt, spermine NONOate) to dislodge biofilms formed by non-typhoidal Salmonella enterica and pathogenic E. coli on plastic and stainless steel surfaces at different temperatures. All five nitric oxide donors induced significant (35-80\%) dispersal of biofilms, however, the degree of dispersal and the optimal dispersal conditions varied. MAHMA NONOate and molsidomine were strong dispersants of the Salmonella biofilms formed on polystyrene. Importantly, molsidomine induced dispersal of up to 50\% of the pre-formed Salmonella biofilm at $4^{\circ} \mathrm{C}$, suggesting that it could be effective even under refrigerated conditions. Biofilms formed by E. coli O157:H7 were also significantly dispersed. Nitric oxide donor molecules were highly active within 6 hours of application. To better understand mode of action of these compounds, we identified Salmonella genomic region recA-hydN, deletion of which led to an insensitivity to the nitric oxide donors.
\end{abstract}

Keywords: Biofilm control; Bacterial signaling; Food-borne pathogens; Nitric oxide

\section{Introduction}

Every natural wet surface is a substrate for microbial biofilms. These sessile multicellular microbial consortia are embedded within the self-produced extracellular polymeric substances (EPS) (Costerton et al. 1987; Marvasi et al. 2010; Solano et al. 2002; Wingender et al. 1999). In food handling facilities, biofilms could be particularly problematic. While pathogens do not typically make up the bulk of the biofilms formed in the industrial settings, Salmonella spp, Listeria spp, pathogenic strains of E. coli, Yersinia spp, Pseudomonas spp, Shigella spp, Staphylococcus spp, and Bacillus spp can be found in biofilms on various contact surfaces (Blanpain-Avet et al. 2011; Shi and Zhu 2009). Because microbes in biofilms are significantly more resistant

\footnotetext{
* Correspondence: maxtep@ufl.edu

'Soil and Water Science Department, University of Florida-IFAS, Gainesville, FL, USA

${ }^{3}$ Cancer and Genetics Research Center, Genetics Institute, 2033 Mowry Road, Gainesville, FL 32611, USA

Full list of author information is available at the end of the article
}

to chlorine and other disinfectants (Zhang and Mah 2008), there is a pressing need to identify compounds capable of controlling biofilms by other means.

A discovery of the nitric oxide's function in inducing biofilm dispersal led to concerted efforts on the identification of the compounds capable of dislodging biofilms (Landini et al. 2010; McDougald et al. 2012). Several disinfectants, antibiotics and messenger molecules have been studied for their ability to disperse biofilms (Barraud et al. 2006; Barraud et al. 2012; Barraud et al. 2009a; Huynh et al. 2012; McDougald et al. 2012). Nitric oxide (NO) gas and NO donors are currently used clinically (RegevShoshani et al. 2010). In bacteria and eukaryotes, nitric oxide is a signaling molecule, active at very low concentrations (Gaupels et al. 2011; Simontacchi et al. 2013). At low concentrations, it is effective as a biofilm dispersant, functioning as a messenger rather than a generic poison (Barraud et al. 2006; Barraud et al. 2009a). Nitric oxide can be delivered to biofilms using $\mathrm{NO}$ donor molecules 
or impregnated onto nanoparticles (Slomberg et al. 2013; Wang et al. 2005). The application of NO donors has the same effect on dispersal of biofilms as the direct addition of nitric oxide and is less toxic than the application of the nitric oxide gas (Barraud et al. 2009a). Over 105 NO donors have been characterized, but only few of them have been tested for controlling industrial biofilms (Wang et al. 2005). Among these, activity of sodium nitroprusside has been recently characterized in detail. It can produce a flux of nitric oxide of $30 \mathrm{pmol} \mathrm{cm}^{-2} \mathrm{~s}^{-1}$, and this can efficiently reduce the adhesion of Staphylococcus aureus, Staphylococcus epidermidis, and E. coli by $96 \%$, $48 \%$, and $88 \%$, respectively (Charville et al. 2008). Therefore, it appears that nitric oxide could have a universal effect on the dispersal of bacterial biofilm including both Gram-positive and Gram-negative bacteria (Xiong and Liu 2010).

In this work, we tested the effectiveness of NO donors in dispersal of biofilms formed by common foodborne pathogens (non-typhoidal Salmonella enterica and enterohaemorrhagic E. coli, EHEC) on materials that are common in the food industry. The rationale for this study was based on the reports that the same NO donors have different dispersion potential depending on the bacterial strain, temperature and surface properties (Barraud et al. 2006; Barraud et al. 2009a; Charville et al. 2008; Gilberthorpe and Poole 2008). Because the ultimate goal of these experiments is to identify commercially available compounds for industrial applications, the following criteria were used to select candidate compounds: 1 ) low/moderate toxicity; 2) have no more than $0.1 \%$ of probable, possible or confirmed human carcinogenicity according to the International Agency for Research on Cancer (IARC); 3) low/moderate cost; 4) commercially availability. Based on these criteria, the following compounds were selected: molsidomine (N- (ethoxycarbonyl)3- (4- morpholinyl)- sydnone imine), MAHMA NONOate (6-(2-Hydroxy-1-methyl-2-nitrosohydrazino)-N-methyl-1hexanamine), spermine NONOate (N-[4-[1-(3-Aminopropyl)2-hydroxy-2-nitrosohydrazino]butyl]-1,3-propanediamine), diethylamine NONOate diethylammonium salt, and diethylamine NONOate sodium.

The mechanisms by which $\mathrm{NO}$ effects the transition from sessile biofilm organisms to free-swimming bacteria are not entirely clear (Barraud et al. 2006; Barraud et al. 2009a).

Microarray studies have revealed that $P$. aeruginosa genes involved in adherence are down regulated upon exposure to nitric oxide (Firoved et al. 2004), and the involvement of $\mathrm{NO}$ in regulating biofilm formation and dispersal in $P$. aeruginosa was also supported by several studies (Barraud et al. 2006; Barraud et al. 2009a; Darling and Evans 2003; Van Alst et al. 2007). Several genes involved in the production and perception of this signaling molecule have been characterized in Pseudomonas aeruginosa PAO1. The chemotaxis protein BdlA is involved in biofilm dispersion of $P$. aeruginosa: biofilms formed by the $b d l A$ mutant do not detach when exposed to low doses of $\mathrm{NO}$ in continuous-flow cultures (Barraud et al. 2009a; Petrova and Sauer 2012). P. aeruginosa nirS and norCB encode a $\mathrm{NO}_{2}{ }^{-}$reductase and $\mathrm{NO}$ reductase. A mutation in nirS leads to a reduced biofilm dispersion (Barraud et al. 2006), while biofilms formed by a NO reductasedeficient strain $\triangle$ nor $C B$ did not shift to the planktonic state when exposed to endogenous nitric oxide. No homologs of NirS, NorCB are found in Salmonella. However, when grown anaerobically with nitrate, Salmonella is capable of generating NO after nitrite addition, likely via products of $f n r$ and $h m p$ genes (Gilberthorpe and Poole 2008). Because the mechanisms of nitric oxide-mediated signaling in Salmonella appear to be distinct from those in $P$. aeruginosa, this study also attempted to elucidate genes that are potentially involved in these signaling pathways and contribute to biofilm dispersal in Salmonella.

\section{Materials and methods}

\section{Bacterial strains and culture media}

Escherichia coli EHEC O157:H7 ATCC 43888, Salmonella enterica serotovar Typhimurium ATCC14028, sv. Braenderup 04E01347, Braenderup 04E01556, Braenderup 04E00783, sv. Montevideo LJH519, sv. Javiana ATCC BAA-1593 and sv. Newport C6.3 (Noel et al. 2010) were used in this study. When a cocktail of Salmonella strains was used, it was a mix of equal volumes of six strains: three strains of the serovar Braenderup (04E01347, 04E01556, 04E00783), sv. Montevideo LJH519, Javiana (ATCC BAA-1593) and Newport (C6.3). pGFP-ON (a strongly fluorescent construct carrying GFP protein expressed from the Salmonella $d p p A$ promoter (Noel et al. 2010)) was transformed into the strains of interest by electroporation.

$S$. Typhimurium A9 is derived from $S$. Typhimurium ATCC14028 and lacks the genomic region between 2,974,854 and 2,990,668 nt of NC_003197.1 (recA through hydN), which was replaced with a kanamycin-resistance cassette. It was constructed by sequential Datsenko and Wanner mutagenesis as in (Santiviago et al. 2009).

All strains were maintained as frozen glycerol stocks, and were sub-cultured into Luria Bertani medium with appropriate antibiotics $\left(50 \mu \mathrm{g} \mathrm{mL} L^{-1}\right.$ kanamycin, $100 \mu \mathrm{g} \mathrm{mL}{ }^{-1}$ ampicillin).

\section{Nitric Oxide donors}

All were purchased from Sigma Aldrich (St. Luois, MO, USA). For each compound, $1 \mathrm{mmol} \mathrm{L}^{-1}$ stock solutions were prepared in phosphate-buffered saline, $\mathrm{pH} 7.3$ (PBS, Fisher, Waltham, MA, USA) and aliquots were stored at $-80^{\circ} \mathrm{C}$. For the essays, serial dilutions were always prepared fresh in ice-cold PBS just before the 
experiments and used within 5 minutes of their preparation. The biofilm dispersion potential of the five molecules was tested on polystyrene and polypropylene. The ability of molsidomine to disperse biofilms was also tested on stainless steel.

\section{Biofilm formation and dispersal on plastics}

Overnight Luria Bertani cultures of Salmonella or E. coli strains were diluted 1:100 in CFA medium as described previously (Teplitski et al. 2006), and $100 \mu \mathrm{L}$ of the diluted cultures were aliquoted into wells of 96-well polypropylene and polystyrene plates (Fisher, Waltham, MA, USA). Plates with bacteria were incubated for 24 hours at $37^{\circ} \mathrm{C}$ inside a Ziploc bag. Upon completion of the incubation, the medium with planktonic bacteria was removed and serial dilutions of nitric oxide donors in PBS (in $200 \mu \mathrm{L}$ ) were added to the wells with biofilms. Dispersal experiments were conducted at $22^{\circ} \mathrm{C}$ or $4^{\circ} \mathrm{C}$ for 6 and 24 hours. Dispersal was measured by staining the remaining biofilms with $1 \%$ crystal violet in ethanol, as described previously (Merritt et al. 2005; O'Toole and Kolter 1998).

In parallel, to validate the staining approach, detachment of cells from biofilms was also measured by directly monitoring the increase of fluorescence of planktonic cells of $S$. Typhimurium 14028 pGFP-ON using Victor-2 multimode plate reader with a $485 \mathrm{~nm} / 535 \mathrm{~nm}$ excitation/emission filter (Perkin Elmer, Waltham, MA, USA).

\section{Luminescence tests}

Effects of selected NO donors on light production by a constitutively luminescent Salmonella strain were characterized as indirect assessments of toxicity of the compounds. Two hundred microliters of Luria Bertani broth inoculated with the overnight, 1:50 diluted culture of S. Typhimurium 14028 pTIM2442 (harboring the lux$C D A B E$ driven by a strong constitutive phage $\lambda$ promoter, Alagely et al., 2011) were grown in black polystyrene plates (Corning, New York, USA) in presence of serial dilutions of Molsidomine. Molsidomine was diluted in PBS $\left(9.89 \mathrm{gL}^{-1}\right)$ (Fisher Scientific, Waltham, MA, USA) to final concentrations of $10 \mu \mathrm{molL}^{-1}, 10 \mathrm{nmolL}^{-1}$, and $10 \mathrm{pmolL}^{-1}$. PBS was used as a control. Luminescence of $S$. Typhimurium 14028 pTIM2442 was measured over time using Victor-2 multimode plate reader (Perkin Elmer, Waltham, MA, USA). Each experiment included 12 replicas.

\section{Biofilm formation on stainless steel}

Biofilms were formed on the stainless steel culture tube closures (Fisher Scientific, Waltham, MA, USA) essentially as described above for plastics with the following modifications: only dilutions of molsidomine were used, and only 24 hours of contact time was tested. Biofilm dispersal was tested by monitoring fluorescence under a multimode microplate reader equipped with a $485 \mathrm{~nm} /$ $535 \mathrm{~nm}$ excitation/emission filter (Perkin Elmer, Waltham, MA, USA).

\section{Additive effect of the disinfectant SaniDate 12.0 with nitric oxide donors}

Biofilms of $S$. Typhimurium ATCC14028 were set up as above using overnight cultures of the pathogen diluted 1:100 in the CFA medium in wells of 96-well polypropylene plates (Fisher, Waltham, MA, USA). Plates with bacteria were incubated for 24 hours at $37^{\circ} \mathrm{C}$ inside a Ziploc bag. Upon completion of the incubation, the medium with planktonic bacteria was removed and $10 \mathrm{nmolL}^{-1}$ of Molsidomine or MAHMA nonoate were added to the wells with biofilms. As controls, BPS alone was used. Plates were incubated at $22^{\circ} \mathrm{C}$ for 24 hours. Upon completion of the incubation, planktonic cells were removed, wells were washed twice with PBS and $200 \mu \mathrm{L}$ of SaniDade 12.0 (BioSafe System, Hartford, CT, USA) diluted as per manufacturer's recommendations and were loaded into the wells. The disinfectant was incubated for 10 minutes, after the incubation time, biofilm dispersal was measured by staining the remaining biofilms with $1 \%$ crystal violet in ethanol, as described previously (Merritt et al. 2005; O’Toole and Kolter 1998). 12 replicas for each experiment were done.

\section{Statistical analysis}

The statistical software JMP (SAS) package was used to infer the One-way ANOVA analysis $(\mathrm{p}<0.05)$. Tukey means separation analysis was inferred in order to group the means.

\section{Results}

\section{Biofilm formation on different plastics}

More robust biofilms were formed by Salmonella and E. coli strains on polypropylene than on polystyrene (Additional file 1: Figure S1). On polypropylene and polystyrene, S. enterica sv Typhimurium 14028 formed more biofilms under these conditions than E. coli O157:H7 (Additional file 1: Figure S1). Biofilm formation is known to vary depending on the surface, the media used to develop biofilms, as well as the protocol adopted (Kroupitski et al. 2009; Teplitski et al. 2006).

\section{Biofilm dispersal by molsidomine}

Molsidomine releases nitric oxide and forms polar metabolites rapidly; its half-life is 1 to 2 hours in plasma at pH 7.4 (Rosenkranz et al. 1996). In terms of biofilm dispersal, molsidomine was the most potent molecule. It was effective in dislodging biofilms formed by S. enterica Sv Typhimurium 14028, the cocktail of the six Salmonella outbreak strains and E. coli O157:H7. Molsidomine was particularly effective on polypropylene (Figure 1). It 


\section{The effect of molsidomine on biofilms}

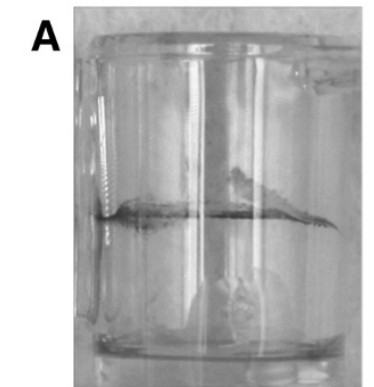

no molsidomine

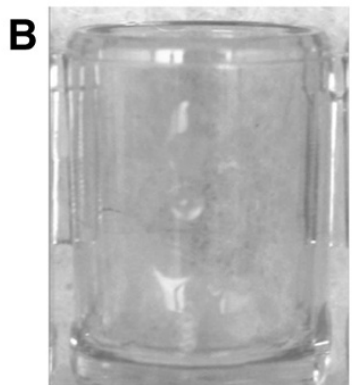

+ molsidomine
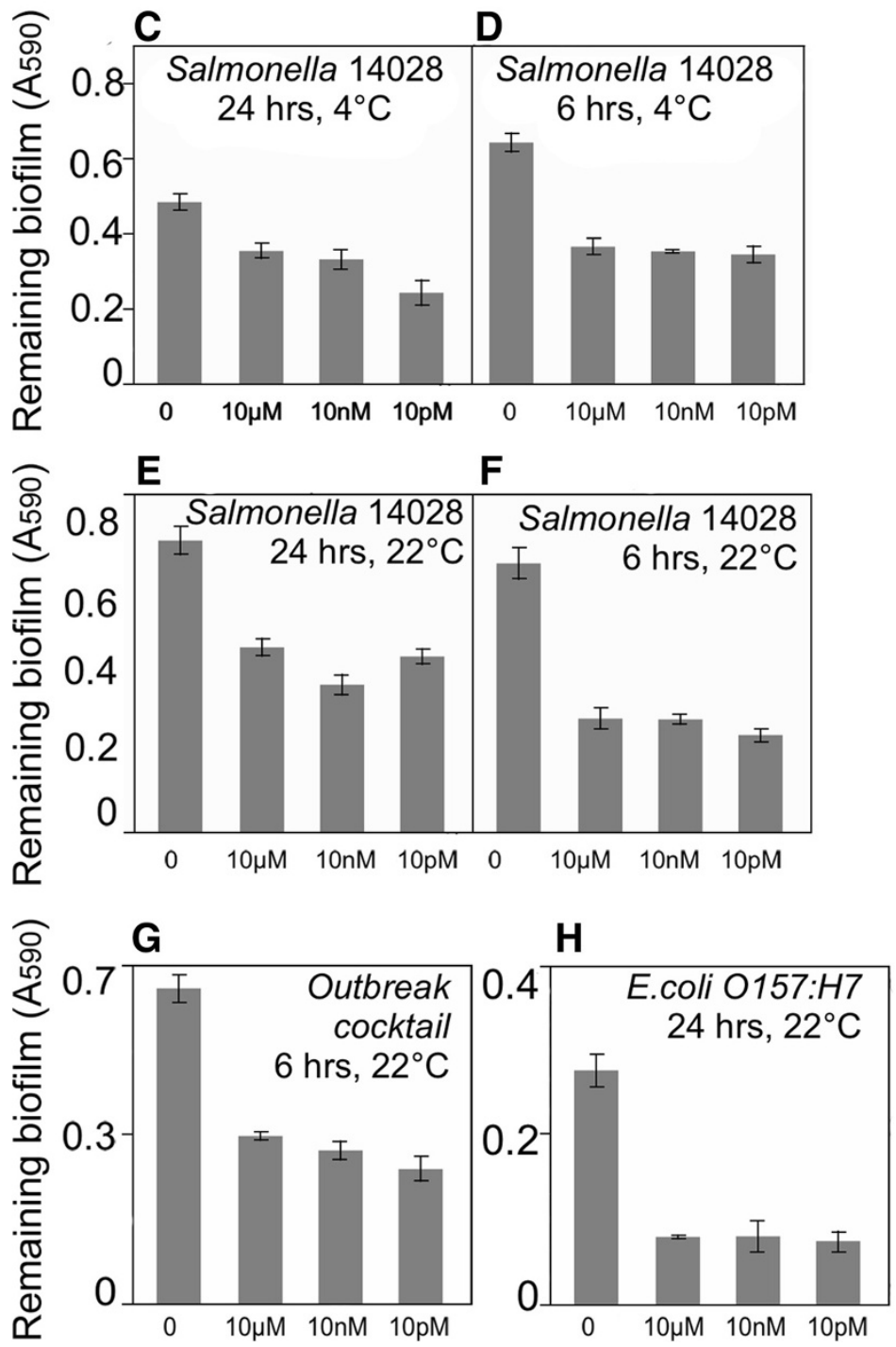

Figure 1 Biofilm dispersal by molsidomine. Exposure to molsidomine doses ranging from $10 \mu \mathrm{M}$ to $10 \mathrm{pM}$ induced biofilm dispersal as measured by staining of the attached cells with crystal violet. " 0 " indicates control, an existing biofilm not treated with molsidomine. A. Biofilm formed by S. enterica sv. Typhimurium 14028 in wells of a microtiter plate before treatment with molsidomine. Attached cells are visualized with crystal violet staining. B. Residual biofilm after treatment with $10 \mathrm{nM}$ of molsidomine. $\mathbf{C} \rightarrow \mathbf{H}$. Induction of biofilm dispersal by molsidomine. Biofilms were pre-formed on polystyrene. Contact time and temperature at which biofilms were exposed to the chemical are listed above each panel. Concentrations of molsidomine are indicated on the $\mathrm{x}$-axis. Error bars are standard errors. 
was most effective at $22^{\circ} \mathrm{C}$, inducing dispersal of $\sim 50 \%$ of biofilms formed by Salmonella 14028 and the cocktail of six Salmonella outbreak strains after incubation for 6 hours (Figure 1, $\mathrm{p}<0.0001$ ). Up to $75 \%$ of biofilm dispersal was observed after a 24-hrs treatment of E. coli O157: H7 biofilms with molsidomine (Figure 1, p $<0.0001$ ). Biofilm dispersal by molsidomine was also observed on polystyrene (Additional file 1: Table S1). Salmonella biofilms preformed in polystyrene wells were dislodged after 24 hours of contact time at room temperature. Molsidomine was able to induce some dispersal even when biofilms were treated with the compound at $4^{\circ} \mathrm{C}$. Intriguingly, the strongest dispersal was observed in response to the treatment with 10 picomolar concentrations of molsidomine (Figure 1). Such potency of the compound at very low concentrations makes it a potentially interesting candidate for commercial applications.

To test whether the decrease in the staining of the attached cells was caused by an increase in the number of planktonic cells, biofilms formed by fluorescent Salmonella 14028 pGFP-ON on polypropylene were treated with molsidomine. Fluorescence of the planktonic and attached cells was measured after 0,3 and 6 hours of exposure to the nitric oxide donor. The increase in total fluorescence of planktonic cells upon treatment of biofilms with molsidomine was statistically significant (Additional file 1: Table S1), reflecting an increase in detachment at the tested concentrations. Similarly, molsidomine treatment of the Salmonella biofilms formed on stainless steel resulted in $\sim 0.3 \log$ increase in fluorescence of the planktonic cells (data not shown).

The ability of the constitutively luminescent Salmonella construct driven by a phage $\lambda$ promoter to produce light in the presence of molsidomine was used as an indirect assessment of the toxicity of the compound, and its ability to generally disrupt metabolism or respiration of the bacteria. As shown in Additional file 1: Figure S2, even though modest decrease in luminescence was observed in molsidomine-treated cultures, the reduction of luminescence was not greater than $1-10 \%$ of the control.

\section{Dose-dependent biofilm dispersal by diethylamine NONOate diethylammonium}

Diethylamine NONOate diethylammonium represents a class of molecules which spontaneously dissociate in a $\mathrm{pH}$-dependent manner, with a half-life of 16 minutes at $22-25^{\circ} \mathrm{C}, \mathrm{pH} 7.4$ to liberate 1.5 moles of $\mathrm{NO}$ per mole of the parental compound (Keefer et al. 1996; Maragos et al. 1991). Biofilm dispersal in response to diethylamine NONOate diethylammonium was dose-dependent (Figure 2), however the relationship was inverse: low concentrations of the nitric oxide were associated with higher biofilm dispersion. The strong activity in the

\section{Biofilm dispersal by diethylamine NONOate diethylammonium}

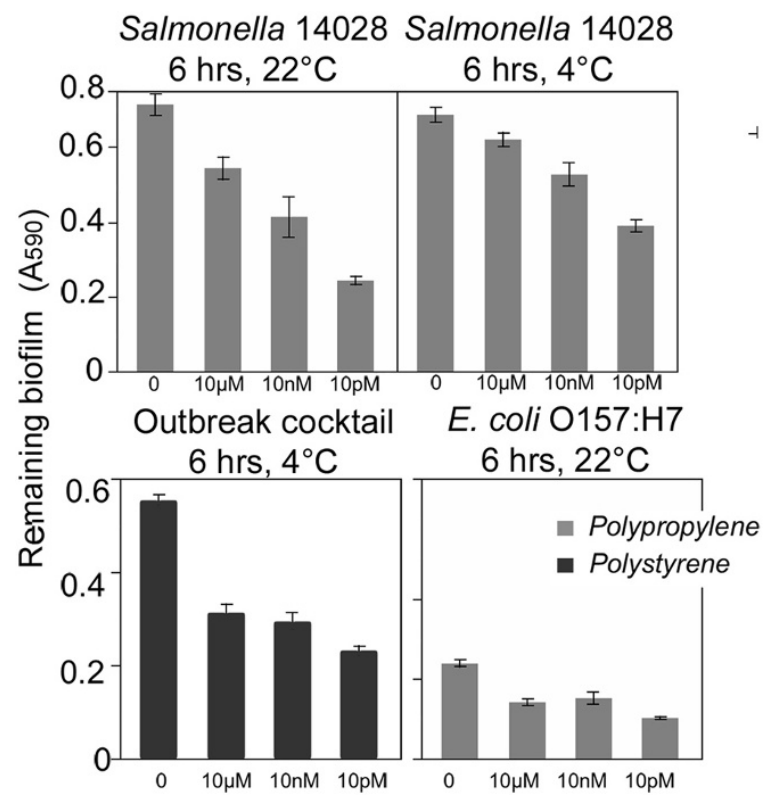

Figure 2 The effect of diethylamine NONOate diethylammonium on biofilms. Remaining biofilms were measured by crystal violet staining, which was solubilized in diluted acetic acid and the absorbance at $590 \mathrm{~nm}$ was measured. Concentrations of the nitric oxide donor are on the $\mathrm{x}$-axis. Contact time and temperature at which pre-formed biofilms were treated with diethylamine NONOate diethylammonium are indicated above each panel.

picomolar range is similar to what was observed with molsidomine.

Diethylamine NONOate diethylammonium was most potent at dispersing biofilms on polypropylene following a 6-hours incubation. A strong dispersal of biofilms formed by Salmonella ATCC 14028 on polypropylene was observed (Figure 2). Biofilms formed by $E$. coli O157:H7 were also dispersed by diethylamine NONOate diethylammonium, but the dispersal was lower when compared with Salmonella. The biofilm formed by the cocktail of six Salmonella outbreak strains formed on polystyrene was also dispersed (Figure 2 and Additional file 1: Table S2 and Additional file 1: Table S3).

The effect of diethylamine NONOate sodium salt hydrate, MAHMA NONOate and spermine NONOate on biofilms Of the tested compounds, diethylamine NONOate sodium salt was the least effective biofilm dispersant following 24 and 6 hours incubation. The strongest dispersion was observed in biofilms formed on polypropylene by the cocktail of Salmonella strains and Salmonella Typhimurium ATCC 14028 (Figure 3). Up to 50\% of reduction of biofilm was detected at room temperature for Salmonella 14028 and the outbreak strains on polystyrene (Figure 3). On 


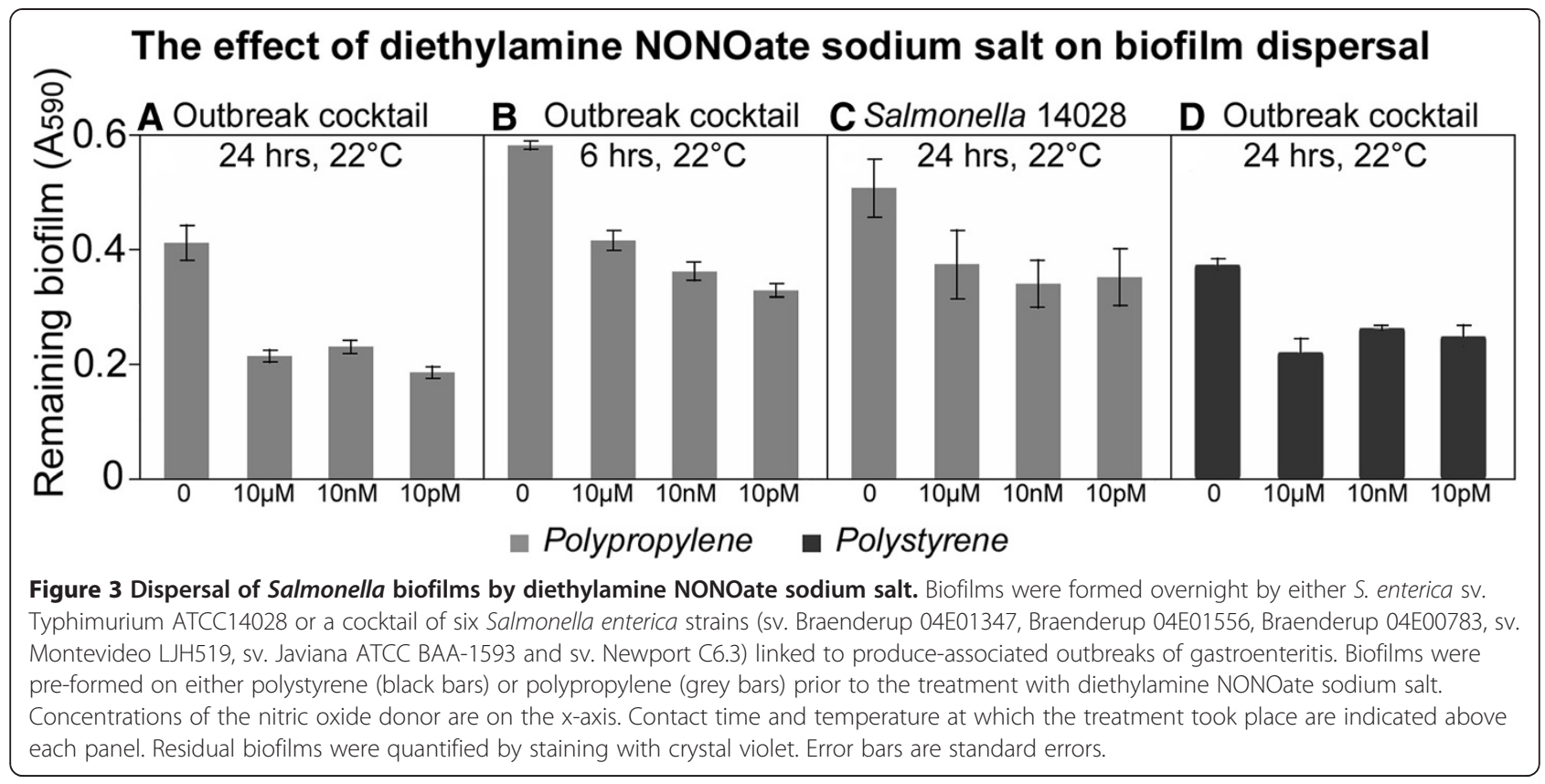

polystyrene, biofilm formation by the cocktail of the Salmonella strains was reduced by up to $30 \%$ when compared with the control. Diethylamine NONOate was also active in dispersing biofilms formed by $E$. coli $\mathrm{O} 157: \mathrm{H} 7$, even though the dispersion was very limited $(\sim 20 \%$ when compared with the control) (Additional file 1: Table S2 and Additional file 1: Table S3).

The effectiveness of MAHMA NONOate (which has half-life of minutes) was compared to that of sperimne NONOate, which has half-life of several hours. This affects potency and sustainability of the treatment, for MAHMA NONOate showing up to 40 times the potency of spermine NONOate, but the latter showing activaty for hours, compared with few minutes for MAHMA NONOate (Wang et al. 2005). MAHMA NONOate is also an optimal dispersant of preformed biofilm of Pseudomonas aerouginosa biofilm (Barnes et al. 2013). Therefore, the two molecules were compared within 6 hours of incubation with Salmonella and E. coli biofilms. As expected MAHMA NONOate was a more effective dispersant on both the materials (Table 1). However, spermine NONOate was mainly effective at releasing biofilms formed on polypropylene (Table 1).

MAHMA NONOate also appears to be a broadly active molecule in dispersing biofilm formed both on polypropylene and polystyrene (Figure 4): it released up to $70 \%$ of $E$. coli biofilms pre-formed on polystyrene at room temperature after a 6-hour treatment (Figure 4). Biofilms formed by $S$. enterica sv Typhimurium ATCC14028 were also dispersed by MAHMA NONOate at room temperature, but compared to spermine NONOate, it was more effective on polystyrene (Figure 4). On polypropylene, up to $50 \%$ of S. enterica sv Typhimurium ATCC14028 and the cocktail of six Salmonella outbreak strains biofilms were dispersed by MAHMA NONOate when incubated for 24 hours at room temperature (Figure 4). Biofilms formed by E. coli O157:H7 were also effectively dispersed on polypropylene but less when compared with polystyrene (Figure 4). Effectiveness of MAHMA nonoate in dispersing

Table 1 The effect of Spermine NONOate and MAHMA NONOate on preformed biofilm

\begin{tabular}{|c|c|c|c|c|}
\hline \multirow[b]{2}{*}{ Material } & \multirow[b]{2}{*}{ Strain } & \multirow[b]{2}{*}{$\begin{array}{l}\text { Incubation } \\
\text { temperature }\end{array}$} & \multicolumn{2}{|c|}{$\begin{array}{l}\text { Probability }>\text { F } \\
(p=0.05)^{*}\end{array}$} \\
\hline & & & $\begin{array}{l}\text { Spermine } \\
\text { NONOate }\end{array}$ & $\begin{array}{l}\text { MAHMA } \\
\text { NONOate }\end{array}$ \\
\hline Polypropylene & Salmonella 14028 & $4^{\circ} \mathrm{C}$ & n.s. & n.s. \\
\hline Polypropylene & Salmonella 14028 & $22^{\circ} \mathrm{C}$ & n.s. & 0.0049 \\
\hline Polypropylene & E.coli O157:H7 & $4^{\circ} \mathrm{C}$ & 0.0273 & n.s. \\
\hline Polypropylene & E.coli O157:H7 & $22^{\circ} \mathrm{C}$ & 0.0486 & $<.0001$ \\
\hline Polypropylene & $\begin{array}{l}\text { Salmonella } \\
\text { cocktail }\end{array}$ & $4^{\circ} \mathrm{C}$ & 0.0036 & 0.0185 \\
\hline Polypropylene & $\begin{array}{l}\text { Salmonella } \\
\text { cocktail }\end{array}$ & $22^{\circ} \mathrm{C}$ & 0.0003 & $<.0001$ \\
\hline Polystyrene & Salmonella 14028 & $4^{\circ} \mathrm{C}$ & 0.0418 & 0.0229 \\
\hline Polystyrene & Salmonella 14028 & $22^{\circ} \mathrm{C}$ & n.s. & $<.0001$ \\
\hline Polystyrene & E.coli O157:H7 & $4^{\circ} \mathrm{C}$ & n.s. & n.s. \\
\hline Polystyrene & E.coli O157:H7 & $22^{\circ} \mathrm{C}$ & n.s. & n.s. \\
\hline Polystyrene & $\begin{array}{l}\text { Salmonella } \\
\text { cocktail }\end{array}$ & $4^{\circ} \mathrm{C}$ & n.s. & 0.0184 \\
\hline Polystyrene & $\begin{array}{l}\text { Salmonella } \\
\text { cocktail }\end{array}$ & $22^{\circ} \mathrm{C}$ & 0.0183 & $<.0001$ \\
\hline
\end{tabular}

*Statistically significant effects $(p<0.05)$ of the NO donor treatments when compared with the untreated control; "n.s." not statistically significant biofilm dispersion. 


\section{Dispersal of biofilms by MAHMA NONOate}

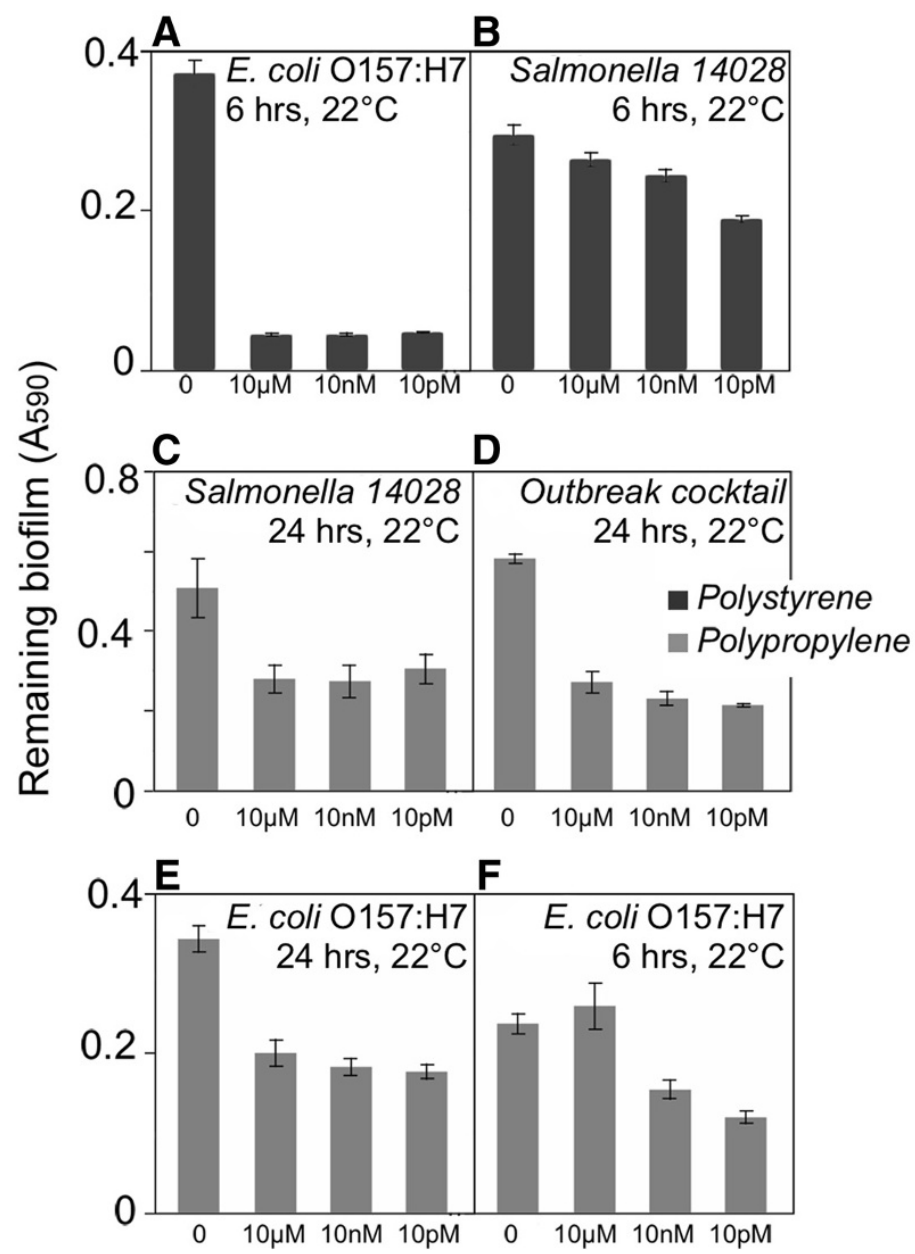

Figure 4 Biofilm dispersal by MAHMA NONOate. Biofilms were formed by E. coli O157:H7, Salmonella sv. Typhimurium 14028 and a cocktail of the six Salmonella strains linked to human produce-related gastroenteritis outbreaks on polystyrene (black bars) or polypropylene (grey bars) prior to the treatment with MAHMA NONOate. Contact times and temperatures at which biofilms were exposed to the nitric oxide donor are listed above each panel. Concentrations of the nitric oxide donor are on the $\mathrm{x}$-axis.

biofilms was further increased by treatment with the microbiocide SaniDate (Figure 5).

\section{The recA-hydN genomic region is involved in Salmonella} biofilm dispersal

In order to better understand how nitric oxide donors induce dispersal of Salmonella biofilms, the genome of S. Typhimurium 14028 was scanned for the homologs of known genes involved in nitric oxide signaling. A mutant lacking the $\sim 15 \mathrm{kB}$ Salmonella enterica sv Typhimurium ATCC14028 genomic region spanning 15 genes (recA-hydN) was studied (Figure 6). This region includes putative NO-reductase machinery: $y g a A$, an anaerobic nitric oxide reductase transcriptional regulator; STM2840, an anaerobic nitric oxide reductase flavorubredoxin; $y g b D$, nitric oxide reductase; hypF, hydrogenase maturation protein; hydN, an electron transport protein HydN. Proteins encoded region can be involved in transferring electron to NO, its detoxification and generation of nitrous oxide. Consistent with the predicted functions of the deleted genes, the $\Delta r e c A-h y d N$ mutant formed a more robust biofilm on polystyrene compared to the wild type, and did not respond to the 24-hrs treatment with molsidomine (Figure 6).

\section{Discussion}

Controlling biofilms on surfaces of clinical and industrial importance has emerged as an important goal. While an impressive toolbox is potentially available to those aiming to prevent microbes from attaching to surfaces and forming biofilms (Campoccia et al. 2013; Chen et al. 2013), the approaches for controlling existing biofilms are significantly 


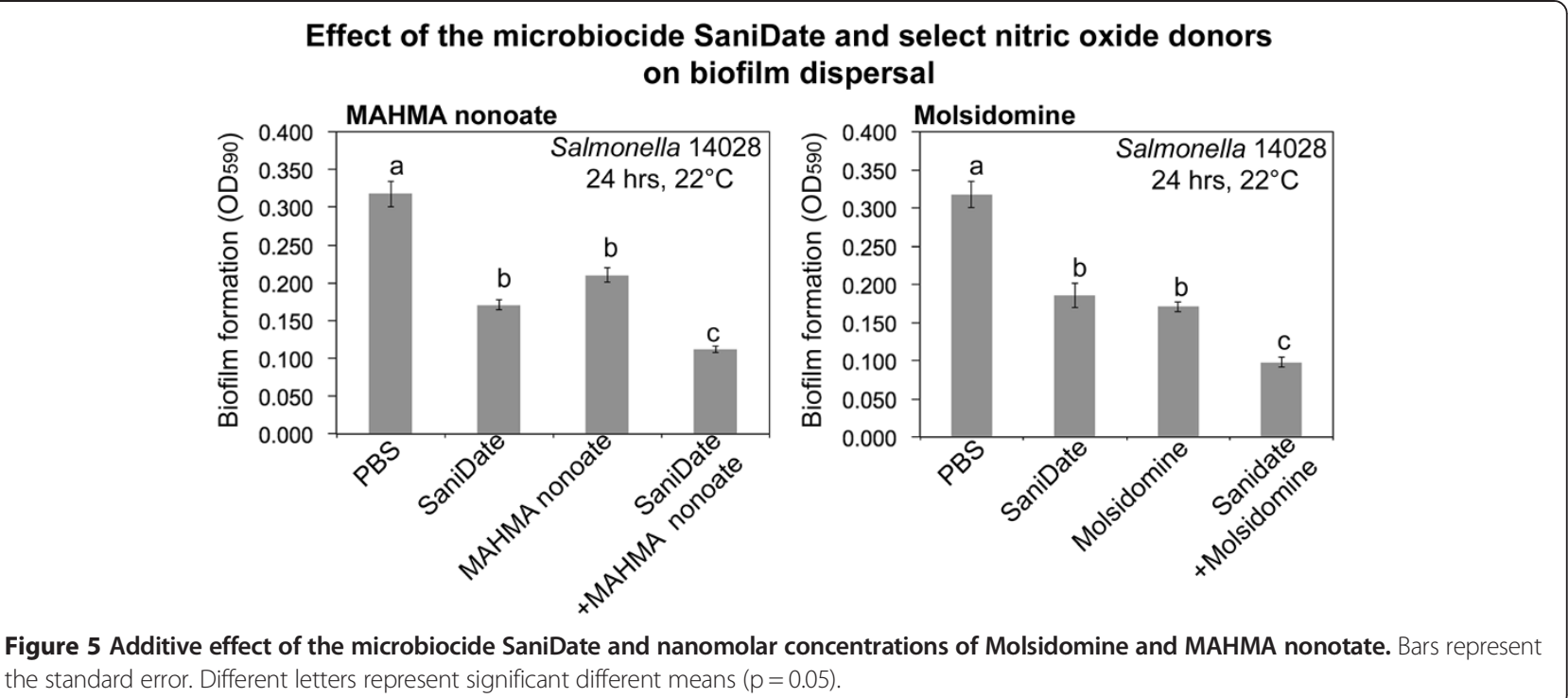

more limited. A seminal discovery that self-produced nitric oxide acts as a dispersal cue for Pseudomonas aeruginosa biofilms (Barraud et al. 2006) sparked interest in exploring the use of the NO gas, molecules and nanoparticles capable of releasing it (Landini et al. 2010; McDougald et al. 2012). Various nitric oxide generating molecules and nanoparticles can be used effectively to dislodge biofilms formed by Gram-negative $P$. aeruginosa and $E$. coli, Gram-Positive Staphylococcus aureus and S. epidermidis (Barraud et al. 2009b; Cherayil and Antos 2001; Slomberg et al. 2013) and prevent attachment of zoospores of the green algae Ulva (Thompson et al. 2010). However, in some bacteria (Shewanella oneidensis, Vibrio harveyi), perception of NO leads to an increased biofilm formation (Landini et al. 2010; Plate and Marletta 2012). Therefore, even though NO is a signal employed by a diversity of organisms, responses to it are not universally conserved. Because of these biological differences in the consequences of NO detection, it is important to establish how and to what extent commercially available nitric oxide donors

\section{Salmonella recA-hydN region is involved in nitric oxide signalling}
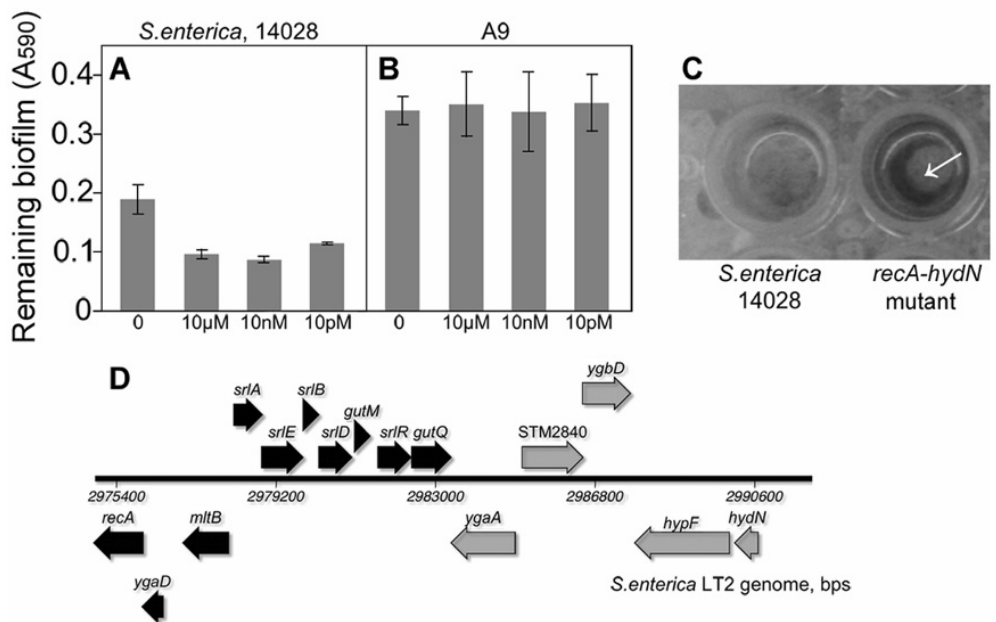

Figure 6 Involvement of the Salmonella recA-hydN genomic region in the nitric oxide-mediated signaling. Salmonella sv. Typhimurium A9 (mutant lacking a $15 \mathrm{kB}$ fragment spanning recA-hydN genes) formed more abundant biofilms, which were not responsive to treatment with nitric oxide donor molsidomine. Detachment of the wild type biofilms in response to molsidomine (A). Lack of response to molsidomine by the A9 mutant (B). Appearance of the biofilms formed by the A9 mutant and the wild type (C). Genomic context of the A9 deletion (D). Thick arrows are annotated ORF. Genes with putative functions in nitric oxide signaling are shaded grey. 
can be used for controlling biofilms formed by important foodborne bacterial pathogens, known to persist as biofilms in the industrial facilities.

With this study, we focused on the effects of off-theshelf NO donors on the biofilms formed by seven strains of $S$. enterica and pathogenic E. coli on surfaces that mimic those found in food processing facilities. The five compounds selected for these tests based on their low potential toxicity, commercial availability and predicted potency demonstrated varying levels of specificity and efficacy. Of the compounds tested, molsidomine and diethylamine NONOate diethylammonium are the most promising as they are capable of dislodging biofilms formed by $S$. Typhimurium 14028, a cocktail of six Salmonella strains isolated from outbreaks and E. coli O157:H7 under most of the tested conditions. For most of the compounds tested, their highest activity appears to be in the picomolar range, suggesting that their applications could be further optimized for the economical and effective industrial applications. The activity of the compounds in the nano- and picomolar ranges further suggests that $\mathrm{NO}$ acts as a potent cue, consistent with previous reports. Low biofilm-dispersing activity of the nitric oxide donors at higher concentrations is, perhaps, not surprising considering that $\mathrm{NO}$ can be bactericidal at a concentration of $\mathrm{mg} \mathrm{L}^{-1}$ (McDougald et al. 2012; Miller et al. 2009), and the methods employed in this study would not necessarily distinguish between live and dead bacteria within an existing biofilm.

Interestingly, some compounds (molsidomine or diethylamine NONOate diethylammonium) were effective at dispersing biofilms under refrigerated conditions $\left(4^{\circ} \mathrm{C}\right)$. Temperature is an important factor affecting the dissociation constant. NONOate (s) are very sensitive to temperature: a $1^{\circ} \mathrm{C}$ change from $37^{\circ} \mathrm{C}$ can results in an approximate $13 \%$ change in NO release (Ramamurthi and Lewis 1997). Therefore, it is reasonable to hypothesize that when biofilms are exposed to the nitric oxide donors at lower temperatures, they experienced the treatment for a longer period of time, and this increased their potency. The implications of this observation for industrial applications are potentially exciting: the ability of the nitric oxide donors to disperse biofilms at $4^{\circ} \mathrm{C}$ makes them good candidates for cleaning refrigerated surfaces, common in the food industry and even removing pathogen biofilms from refrigerated foods. While Salmonella and E. coli are thought to be metabolically inactive under these conditions, their populations in biofilms formed on refrigerated foods remain relatively steady over an extended period of time (Kroupitski et al. 2009). Furthermore, a complement of Salmonella genes that were differentially expressed during biofilm formation on cut lettuce during cold storage has been identified (Kroupitski et al. 2013), suggesting that even though the cells of these human pathogens are not dividing, physiological processes and gene expression still take place under refrigerated conditions. It would be of great interest to determine whether these specific genes induced in biofilms on foods at $4-8^{\circ} \mathrm{C}$ could be subject to manipulation by NO. More broadly, it remains to be determined which of the Salmonella genes involved in biofilm formation (Hamilton et al. 2009; Teplitski et al. 2006) are subject to regulation by nitric oxide, and conversely - which of the known Salmonella genes responsive to nitric oxide contribute to the NO-mediated biofilm dispersal (Henard and Vazquez-Torres 2011; Karlinsey et al. 2012; Richardson et al. 2011).

\section{Additional file}

\begin{abstract}
Additional file 1: Figure S1. Biofilm formation on different plastics by Salmonella and E. coli O157:H7. Biofilms were established on polypropylene and polystyrene surfaces in CFA medium for $24 \mathrm{hrs}$ and stained with 1\% crystal violet and then washed. The absorbed crystal violet and the biofilm were dissolved in 33\% acetic acid and A590 was measured with a spectrophotometer. Error bars represent standard error. Significant different means are displayed with different letters. Figure S2. Luminescence of Salmonella 14028 pTIM2442 upon exposure to molsidomine. General metabolic state of the cells was assessed using the redox-coupled FMNH2/Luciferase produced by a S. Typhimurium ATCC14028 strain harboring high copy number plasmid in which the luxCDABE operon is under the phage $\lambda$ promoter (pTIM2442). Concentrations of molsidomine to which cultures of Salmonella 14028 pTIM2442 were exposed are listed on the figure. Error bars represent the standard error of 12 replicas. Table S1. Fluorescence of the Salmonella cells detached by molsidomine treatment Measurement of Salmonella 14028 planktonic cells detached from preformed biofilm during treatment with molsidomine. polypropylene, *Statistically significant effects $(p<0.05)$ of molsidomine treatment. Table S2. The complete set of experiments on the effect of the NO donors on preformed biofilm after 24 hours of contact time. *Statistically significant effects $(p<0.05)$ of the $\mathrm{NO}$ donor treatments. n.S., not statistically significant biofilm dispersion. MOL, Molsidomine; M1555, MAHMA NONOate; S150, SPERMINE NONOate; D5431, diethylamine NONOate diethylammonium salt; D184, diethylamine NONOate sodium; S8432 sulfo NONOate disodium salt. Table S3. The complete set of experiments on the effect of the NO donors on preformed biofilm after 6 hours of contact time. *Statistically significant effects $(p<0.05)$ of the NO donor treatments. n.s., not statistically significant biofilm dispersion. $\mathrm{MOL}$ Molsidomine; M1555, MAHMA NONOate; S150, SPERMINE NONOate; D5431, diethylamine NONOate diethylammonium salt; D184, diethylamine NONOate sodium; S8432 sulfo NONOate disodium salt.
\end{abstract}

\section{Competing interests}

This research was supported by funding provided by the Florida Tomato Committee, Grant \#106486 and by the UC-Davis Center for Produce Safety, Grant \#2014-308.

\section{Authors' contributions}

MM, MT conceived experiments; MM, CC, MC, IAD conducted experiments; MM analyzed data; MM, MT wrote the manuscript. All authors read and approved the final manuscript.

\section{Acknowledgements}

We are grateful to M. McClelland for providing A9 mutant.

\section{Author details}

'Soil and Water Science Department, University of Florida-IFAS, Gainesville, FL, USA. ${ }^{2}$ Microbiology and Cell Science Department, University of Florida-IFAS, Gainesville, FL, USA. ${ }^{3}$ Cancer and Genetics Research Center, Genetics Institute, 2033 Mowry Road, Gainesville, FL 32611, USA. 
Received: 31 March 2014 Accepted: 10 April 2014

\section{Published online: 05 June 2014}

\section{References}

Alagely A, Rajamani S, Teplitski M (2011) Luminescent reporters and their applications for the characterization of signals and signal-mimics that alter LasR-mediated quorum sensing. Methods Mol Biol 692:113-130. doi:10.1007/ 978-1-60761-971-0_9

Barnes RJ, Bandi RR, Wong WS, Barraud N, McDougald D, Fane A, Kjelleberg S, Rice SA (2013) Optimal dosing regimen of nitric oxide donor compounds for the reduction of Pseudomonas aeruginosa biofilm and isolates from wastewater membranes. Biofouling 29(2):203-212. doi:10.1080/08927014.2012.760069

Barraud N, Hassett DJ, Hwang SH, Rice SA, Kjelleberg S, Webb JS (2006) Involvement of nitric oxide in biofilm dispersal of Pseudomonas aeruginosa. J Bacteriol 188(21):7344-7353. doi:10.1128/JB.00779-06

Barraud N, Schleheck D, Klebensberger J, Webb JS, Hassett DJ, Rice SA, Kjelleberg S (2009a) Nitric oxide signaling in Pseudomonas aeruginosa biofilms mediates phosphodiesterase activity, decreased cyclic di-GMP levels, and enhanced dispersal. J Bacteriol 191(23):7333-7342. doi:10.1128/JB.00975-09

Barraud N, Storey MV, Moore ZP, Webb JS, Rice SA, Kjelleberg S (2009b) Nitric oxide-mediated dispersal in single- and multi-species biofilms of clinically and industrially relevant microorganisms. Microb Biotechnol 2(3):370-378. doi:10.1111/j.1751-7915.2009.00098.x

Barraud N, Kardak BG, Yepuri NR, Howlin RP, Webb JS, Faust SN, Kjelleberg S, Rice SA, Kelso MJ (2012) Cephalosporin-3'-diazeniumdiolates: targeted NO-donor prodrugs for dispersing bacterial biofilms. Angew Chem Int Ed Engl 51 (36):9057-9060. doi:10.1002/anie.201202414

Blanpain-Avet P, Faille C, Delaplace G, Bénézech T (2011) Cell adhesion and related fouling mechanism on a tubular ceramic microfiltration membrane using Bacillus cereus spores. J Membrane Sci 385-386(0):200-216, doi:http:// dx.doi.org/10.1016/j.memsci.2011.09.041

Campoccia D, Montanaro L, Arciola CR (2013) A review of the biomaterials technologies for infection-resistant surfaces. Biomaterials 34(34):8533-8554. doi:10.1016/j.biomaterials.2013.07.089

Charville GW, Hetrick EM, Geer CB, Schoenfisch MH (2008) Reduced bacterial adhesion to fibrinogen-coated substrates via nitric oxide release. Biomaterials 29(30):4039-4044. doi:10.1016/j.biomaterials.2008.07.005

Chen M, Yu Q, Sun H (2013) Novel strategies for the prevention and treatment of biofilm related infections. Int J Mol Sci 14(9):18488-18501. doi:10.3390/ ijms140918488

Cherayil BJ, Antos D (2001) Inducible nitric oxide synthase and Salmonella infection. Microbes Infect 3(9):771-776

Costerton JW, Cheng KJ, Geesey GG, Ladd TI, Nickel JC, Dasgupta M, Marrie TJ (1987) Bacterial biofilms in nature and disease. Annu Rev Microbiol 41:435-464. doi:10.1146/annurev.mi.41.100187.002251

Darling KE, Evans TJ (2003) Effects of nitric oxide on Pseudomonas aeruginosa infection of epithelial cells from a human respiratory cell line derived from a patient with cystic fibrosis. Infect Immun 71(5):2341-2349

Firoved AM, Wood SR, Ornatowski W, Deretic V, Timmins GS (2004) Microarray analysis and functional characterization of the nitrosative stress response in nonmucoid and mucoid Pseudomonas aeruginosa. J Bacteriol 186(12):4046-4050. doi:10.1128/JB.186.12.4046-4050.2004

Gaupels F, Kuruthukulangarakoola GT, Durner J (2011) Upstream and downstream signals of nitric oxide in pathogen defence. Curr Opin Plant Biol 14(6):707-714. doi:10.1016/j.pbi.2011.07.005

Gilberthorpe NJ, Poole RK (2008) Nitric oxide homeostasis in Salmonella typhimurium: roles of respiratory nitrate reductase and flavohemoglobin. J Biol Chem 283(17):11146-11154. doi:10.1074/jbc.M708019200

Hamilton S, Bongaerts RJ, Mulholland F, Cochrane B, Porter J, Lucchini S, Lappin-Scott HM, Hinton JC (2009) The transcriptional programme of Salmonella enterica serovar Typhimurium reveals a key role for tryptophan metabolism in biofilms. BMC Genomics 10:599. doi:10.1186/1471-2164-10-599

Henard CA, Vazquez-Torres A (2011) Nitric oxide and Salmonella pathogenesis. Front Microbiol 2:84. doi:10.3389/fmicb.2011.00084

Huynh T, McDougald D, Klebensberger J, Al Qarni B, Barraud N, Rice SA, Kjelleberg S, Schleheck D (2012) Glucose starvation-induced dispersal of Pseudomonas aeruginosa biofilms is CAMP and energy dependent. PLoS One 7(8):e42874. doi:10.1371/journal.pone.0042874

Karlinsey JE, Bang IS, Becker LA, Frawley ER, Porwollik S, Robbins HF, Thomas VC, Urbano R, McClelland M, Fang FC (2012) The NsrR regulon in nitrosative stress resistance of Salmonella enterica serovar Typhimurium. Mol Microbiol 85(6):1179-1193. doi:10.1111/j.1365-2958.2012.08167.x

Keefer LK, Nims RW, Davies KM, Wink DA (1996) "NONOates" (1-substituted diazen-1-ium-1,2-diolates) as nitric oxide donors: Convenient nitric oxide dosage forms. In: Lester P (ed) Methods in Enzymology. vol Volume 268. Academic Press, New York, pp 281-293

Kroupitski Y, Pinto R, Brandl MT, Belausov E, Sela S (2009) Interactions of Salmonella enterica with lettuce leaves. J Appl Microbiol 106(6):1876-1885. doi:10.1111/j.1365-2672.2009.04152.x

Kroupitski Y, Brandl MT, Pinto R, Belausov E, Tamir-Ariel D, Burdman S, Sela Saldinger S (2013) Identification of Salmonella enterica genes with a role in persistence on lettuce leaves during cold storage by Recombinase-based in Vivo Expression Technology. Phytopathology 103(4):362-372. doi:10.1094/PHYTO-10-12-0254-FI

Landini P, Antoniani D, Burgess JG, Nijland R (2010) Molecular mechanisms of compounds affecting bacterial biofilm formation and dispersal. Appl Microbiol Biotechnol 86(3):813-823. doi:10.1007/s00253-010-2468-8

Maragos CM, Morley D, Wink DA, Dunams TM, Saavedra JE, Hoffman A, Bove AA, Isaac L, Hrabie JA, Keefer LK (1991) Complexes of NO with nucleophiles as agents for the controlled biological release of nitric oxide: Vasorelaxant effects. J Med Chem 34(11):3242-3247. doi:10.1021/jm00115a013

Marvasi M, Visscher PT, Casillas Martinez L (2010) Exopolymeric substances (EPS) from Bacillus subtilis: polymers and genes encoding their synthesis. FEMS Microbiol Lett 313(1):1-9. doi:10.1111/j.1574-6968.2010.02085.x

McDougald D, Rice SA, Barraud N, Steinberg PD, Kjelleberg S (2012) Should we stay or should we go: mechanisms and ecological consequences for biofilm dispersal. Nat Rev Micro 10(1):39-50

Merritt JH, Kadouri DE, O'Toole GA (2005) Growing and analyzing static biofilms. Curr Protoc Microbiol Chapter 1:Unit 1B 1, doi:10.1002/9780471729259. mc01b01s00

Miller C, McMullin B, Ghaffari A, Stenzler A, Pick N, Roscoe D, Ghahary A, Road J, Av-Gay Y (2009) Gaseous nitric oxide bactericidal activity retained during intermittent high-dose short duration exposure. Nitric Oxide 20(1):16-23. doi:10.1016/j.niox.2008.08.002

Noel JT, Arrach N, Alagely A, McClelland M, Teplitski M (2010) Specific responses of Salmonella enterica to tomato varieties and fruit ripeness identified by in vivo expression technology. PLoS One 5(8):e12406. doi:10.1371/journal.pone.0012406

OToole GA, Kolter R (1998) Initiation of biofilm formation in Pseudomonas fluorescens WCS365 proceeds via multiple, convergent signalling pathways: a genetic analysis. Mol Microbiol 28(3):449-461

Petrova OE, Sauer K (2012) Dispersion by Pseudomonas aeruginosa requires an unusual posttranslational modification of BdIA. Proc Natl Acad Sci U S A 109 (41):16690-16695. doi:10.1073/pnas.1207832109

Plate L, Marletta MA (2012) Nitric oxide modulates bacterial biofilm formation through a multicomponent cyclic-di-GMP signaling network. Mol Cell 46 (4):449-460. doi:10.1016/j.molcel.2012.03.023

Ramamurthi A, Lewis RS (1997) Measurement and modeling of nitric oxide release rates for nitric oxide donors. Chem Res Toxicol 10(4):408-413. doi:10.1021/tx960183w

Regev-Shoshani G, Ko M, Miller C, Av-Gay Y (2010) Slow release of nitric oxide from charged catheters and its effect on biofilm formation by Escherichia coli. Antimicrob Agents Chemother 54(1):273-279. doi:10.1128/AAC.00511-09

Richardson AR, Payne EC, Younger N, Karlinsey JE, Thomas VC, Becker LA, Navarre WW, Castor ME, Libby SJ, Fang FC (2011) Multiple targets of nitric oxide in the tricarboxylic acid cycle of Salmonella enterica serovar typhimurium. Cell Host Microbe 10(1):33-43. doi:10.1016/j.chom.2011.06.004

Rosenkranz B, Winkelmann BR, Parnham MJ (1996) Clinical pharmacokinetics of molsidomine. Clin Pharmacokinet 30(5):372-384

Santiviago CA, Reynolds MM, Porwollik S, Choi S-H, Long F, Andrews-Polymenis $\mathrm{HL}$, McClelland M (2009) Analysis of pools of targeted Salmonella deletion mutants identifies novel genes affecting fitness during competitive infection in mice. PLoS Pathog 5(7):e1000477. doi:10.1371/journal.ppat.1000477

Shi X, Zhu X (2009) Biofilm formation and food safety in food industries. Trend Food Sci Technol 20(9):407-413, doi:http://dx.doi.org/10.1016/j.tifs.2009.01.054

Simontacchi M, García-Mata C, Bartoli CG, Santa-María GE, Lamattina L (2013) Nitric oxide as a key component in hormone-regulated processes. Plant Cell Rep 32(6):853-866. doi:10.1007/s00299-013-1434-1

Slomberg DL, Lu Y, Broadnax AD, Hunter RA, Carpenter AW, Schoenfisch MH (2013) Role of size and shape on biofilm eradication for nitric oxide-releasing silica nanoparticles. ACS Appl Mater Interfaces 5:19. doi:10.1021/am402618w 
Solano C, Garcia B, Valle J, Berasain C, Ghigo JM, Gamazo C, Lasa I (2002) Genetic analysis of Salmonella enteritidis biofilm formation: critical role of cellulose. Mol Microbiol 43(3):793-808

Teplitski M, Al-Agely A, Ahmer BMM (2006) Contribution of the SirA regulon to biofilm formation in Salmonella enterica serovar Typhimurium. Microbiology 152(11):3411-3424. doi:10.1099/mic.0.29118-0

Thompson SE, Callow ME, Callow JA (2010) The effects of nitric oxide in settlement and adhesion of zoospores of the green alga Ulva. Biofouling 26(2):167-178. doi:10.1080/08927010903402420

Van Alst NE, Picardo KF, Iglewski BH, Haidaris CG (2007) Nitrate sensing and metabolism modulate motility, biofilm formation, and virulence in Pseudomonas aeruginosa. Infect Immun 75(8):3780-3790. doi:10.1128//AI.00201-07

Wang PG, Cai TB, Taniguchi N (2005) Nitric Oxide Donors. Wiley-VCH Verlag $\mathrm{GmbH} \& \mathrm{Co}, \mathrm{KGaA}$

Wingender J, Neu TR, Flemming HC (1999) Microbial Extracellular Polymeric Substances: Characterization, Structure, and Function. Springer, New York

Xiong Y, Liu Y (2010) Biological control of microbial attachment: a promising alternative for mitigating membrane biofouling. Appl Microbiol Biotechnol 86(3):825-837. doi:10.1007/s00253-010-2463-0

Zhang L, Mah TF (2008) Involvement of a novel efflux system in biofilm-specific resistance to antibiotics. J Bacteriol 190(13):4447-4452. doi:10.1128/JB.01655-07

doi:10.1186/s13568-014-0042-y

Cite this article as: Marvasi et al.: Systematic analysis of the ability of Nitric Oxide donors to dislodge biofilms formed by Salmonella enterica and Escherichia coli O157:H7. AMB Express 2014 4:42.

\section{Submit your manuscript to a SpringerOpen ${ }^{\circ}$} journal and benefit from:

- Convenient online submission

- Rigorous peer review

- Immediate publication on acceptance

- Open access: articles freely available online

- High visibility within the field

- Retaining the copyright to your article

Submit your next manuscript at $\gg$ springeropen.com 